\title{
The response of the North American Monsoon to increased greenhouse gas forcing
}

\author{
B. I. Cook ${ }^{1,2}$ and R. Seager ${ }^{2}$ \\ Received 31 July 2012; revised 8 November 2012; accepted 14 December 2012; published 27 February 2013.
}

[1] We analyze the response of the North American Monsoon (NAM) to increased greenhouse gas (GHG) forcing (emissions scenario RCP 8.5) using new simulations available through the Coupled Model Intercomparison Project version 5 (CMIP5). Changes in total monsoon season rainfall with GHG warming are small and insignificant. The models do, however, show significant declines in early monsoon season precipitation (June-July) and increases in late monsoon season (September-October) precipitation, indicating a shift in seasonality toward delayed onset and withdrawal of the monsoon. Early in the monsoon season, tropospheric warming increases vertical stability, reinforced by reductions in available surface moisture, inhibiting precipitation and delaying the onset of the monsoon. By the end of the monsoon season, moisture convergence is sufficient to overcome the warming induced stability increases, and precipitation is enhanced. Even with no change in total NAM rainfall, shifts in the seasonal distribution of precipitation within the NAM region are still likely to have significant societal and ecological consequences, reinforcing the need to not only understand the magnitude, but also the timing, of future precipitation changes.

Citation: Cook, B. I., and R. Seager (2013), The response of the North American Monsoon to increased greenhouse gas forcing, J. Geophys. Res. Atmos, 118, 1690-1699, doi:10.1002/jgrd.50111.

\section{Introduction}

[2] The North American Monsoon (NAM) dominates the seasonal cycle of precipitation over northwestern Mexico, southern Arizona, and large areas of New Mexico and Texas [Adams and Comrie, 1997; Barlow et al., 1998]. Over the core region of the NAM $\left(112^{\circ} \mathrm{W}-102^{\circ} \mathrm{W}, 18^{\circ} \mathrm{N}-33^{\circ} \mathrm{N}\right.$; see Figure 1), the summer monsoon rainfall peaks during July-August-September (JAS), representing over $70 \%$ of the annual rainfall total for the region. Variations in the strength and timing of the NAM can have major consequences for agriculture, rangeland management, and fire [Ray et al., 2007]. Compared to other aspects of western hydroclimate [e.g., Barnett et al., 2008; Seager et al., 2007; Seager and Vecchi, 2010], however, relatively little progress has been made towards improving our understanding of how the NAM will respond to increased greenhouse gas (GHG) forcing in the future. This difficulty can, in part, be attributed to the inability of many coarsely resolved global general circulation models (GCMs, the primary tools for investigating

\footnotetext{
${ }^{1}$ NASA Goddard Institute for Space Studies, 2880 Broadway, New York, New York, USA, 10025.

${ }^{2}$ Lamont-Doherty Earth Observatory, 61 Route 9W, Palisades, New York, USA, 10964

Corresponding author: B. I. Cook, NASA Goddard Institute for Space Studies, 2880 Broadway, New York, New York, USA, 10025. (benjamin.i.cook@nasa.gov)

(C)2013. American Geophysical Union. All Rights Reserved. 2169-897X/13/10.1002/jgrd.50111
}

future climate) to realistically simulate the fine scale topography and dynamics over the NAM region [Kim et al., 2008].

[3] Recent studies have found that many monsoon regions, including the NAM, respond to increased GHG forcing by shifting their precipitation seasonality [Biasutti and Sobel, 2009; Seth et al., 2011]. This shift in seasonality manifests as a reduction in early monsoon season rainfall and delayed onset, followed by increased precipitation late in the monsoon season and a delayed withdrawal. Early season precipitation reductions are due to an enhanced convective barrier in the spring that inhibits convection and cloud formation in the spring and early summer, weakening and delaying the monsoon. The enhanced convective barrier arises through two processes: a local mechanism, where reduced evapotranspiration (ET) reduces surface moisture availability, and a remote mechanism, where GHG induced atmospheric warming increases tropospheric stability. Once the summer monsoon circulation is fully established, increased moisture convergence is able to overcome this enhanced convective barrier, destabilizing the atmosphere and leading to increased precipitation. Dynamically, this pattern of reduced rainfall early in the monsoon (when conditions are relatively dry) and enhanced rainfall during the late monsoon season (when the monsoon circulation is fully established) is analogous to the 'uppedante' mechanism described by Neelin et al. [2003]. In addition to at least one modeling study [Seth et al., 2011], there is some empirical evidence that the timing of the NAM has shifted in recent decades [Grantz et al., 2007], evidenced by delays in the onset, peak, and withdrawal of the monsoon that is consistent with the enhanced convective 
The North American Monsoon (GPCC, 1980-1999)
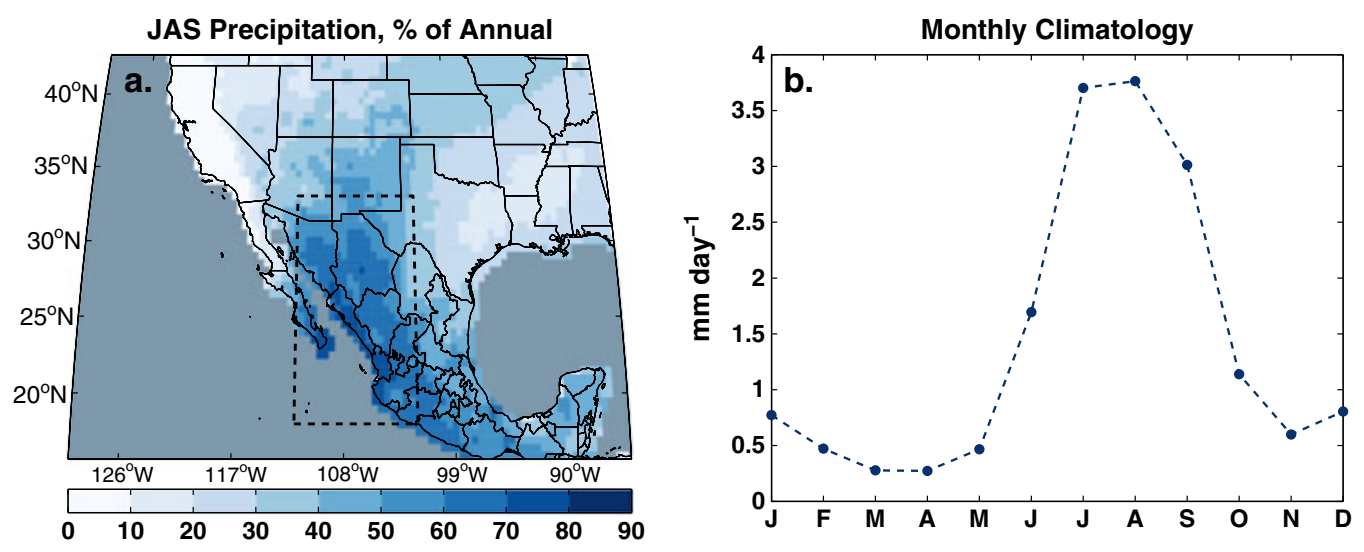

Figure 1. Climatology of the NAM, based on monthly precipitation data from the GPCC at $0.5^{\circ}$ spatial resolution. (a) Percent of annual precipitation falling during the peak NAM season (JAS), with the core NAM region outlined by the black dashed line $\left(112^{\circ} \mathrm{W}-102^{\circ} \mathrm{W}, 18^{\circ} \mathrm{N}-33^{\circ} \mathrm{N}\right)$. (b) Climatological monthly precipitation $\left(\mathrm{mm} \mathrm{day}^{-1}\right)$ averaged over the core of the NAM region.

barrier mechanism. Several studies also point to a positive soil moisture precipitation feedback within the NAM region [Small, 2001; Vivoni et al., 2009], consistent with the local inhibition mechanism.

[4] As part of the Intergovernmental Panel on Climate Change (IPCC) Fifth Assessment Report (AR5), new GCM simulations of modern and potential future climate have been made available through the Coupled Model Intercomparison Project version 5 (CMIP5) [Taylor et al., 2012]. This provides a new opportunity to investigate the response of the NAM to anthropogenic GHG forcing, using a new generation of state of the art GCMs that have, in many cases, higher spatial resolution compared to the previous generation of models. We focus our analysis around two research questions: 1) How does increased GHG forcing affect the magnitude and timing of the NAM? and 2) How consistent are these changes with the local and remote convective inhibition mechanisms?

\section{Materials and Methods}

[5] For our analysis, we use a gridded precipitation data set and historical and potential future GCM simulations from the CMIP5 archive. To facilitate comparisons across models, we linearly interpolated all model output to $1^{\mathrm{o}}$ horizontal resolution. All area averages are based on land areas only from the core NAM region, as defined in the introduction.

\subsection{Precipitation Data}

[6] To validate the simulation of the NAM in the CMIP5 models, we used gridded precipitation data from the Global Precipitation Climatology Centre (GPCC) full

Table 1. Models From the CMIP5 Experiments (Historical and RCP8.5) Used in This Analysis, Including the Modeling Center or Group That Supplied the Output, the Number of Ensemble Members That Met Our Criteria for Inclusion, and the Approximate Spatial Resolution

\begin{tabular}{|c|c|c|c|}
\hline Model & Modeling Center (or Group) & \# Ens. Members & Lat/Lon Resolution \\
\hline CCSM4 & NCAR $^{\mathrm{a}}$ & 5 & $0.94^{\circ} \times 1.25^{\circ}$ \\
\hline CNRM-CM5 & CNRM-CERFACS ${ }^{\mathrm{b}}$ & 5 & $1.4^{\circ} \times 1.4^{\circ}$ \\
\hline CSIRO-MK3.6.0 & CSIRO-QCCCE ${ }^{\mathrm{c}}$ & 10 & $1.875^{\circ} \times 1.875^{\circ}$ \\
\hline CanESM2 & $\mathrm{CCCMA}^{\mathrm{d}}$ & 5 & $2.8^{\circ} \times 2.8^{\circ}$ \\
\hline GFDL-CM3 & NOAA GFDL ${ }^{\mathrm{e}}$ & 1 & $2^{\circ} \times 2.5^{\circ}$ \\
\hline GFDL-ESM2G & NOAA GFDL & 1 & $2^{\circ} \times 2.5^{\circ}$ \\
\hline GFDL-ESM2M & NOAA GFDL & 1 & $2^{\circ} \times 2.5^{\circ}$ \\
\hline HadGEM2-CC & МOHC & 3 & $1.25^{\circ} \times 1.875^{\circ}$ \\
\hline HadGEM2-ES & МОНС ${ }^{f}$ & 4 & $1.25^{\circ} \times 1.875^{\circ}$ \\
\hline MIROC5 & MIROC $^{\mathrm{g}}$ & 3 & $1.4^{\circ} \times 1.4^{\circ}$ \\
\hline MPI-ESM-LR & MPI-M ${ }^{\mathrm{h}}$ & 3 & $1.875^{\circ} \times 1.875^{\circ}$ \\
\hline
\end{tabular}

${ }^{\mathrm{a}}$ National Center for Atmospheric Research.

${ }^{\mathrm{b}}$ Centre National de Recherches Meteorologiques / Centre Europeen de Recherche et Formation Avancees en Calcul Scientifique.

${ }^{\mathrm{c}}$ Commonwealth Scientific and Industrial Research Organization in collaboration with Queensland Climate Change Centre of Excellence.

${ }^{\mathrm{d} C a n a d i a n}$ Centre for Climate Modelling and Analysis

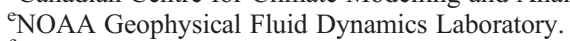

Met Office Hadley Centre.

${ }^{\mathrm{g}}$ Atmosphere and Ocean Research Institute (The University of Tokyo), National Institute for Environmental Studies, and Japan Agency for Marine-Earth Science and Technology.

${ }^{\mathrm{h}}$ Max Planck Institute for Meteorology. 
data reanalysis version 5 [Beck et al., 2005; Rudolf et al., 1994; Rudolf et al., 2003; Rudolf et al., 2005; Rudolf and Schneider, 2004]. The GPCC reanalysis is based on a statistical interpolation of in situ rain gauge observations, continuously covering all global land areas (excluding Antarctica) at monthly temporal resolution and $0.5^{\circ}$ spatial resolution for the years 1901-2009. This product has been used in a variety of analyses [e.g., Rubel and Kottek, 2010;
Wild et al., 2008; Yatagai et al., 2009], including in the assessment of model precipitation over Mexico and western North America [Ruff et al., 2011].

\subsection{CMIP5 Model Simulations}

[7] To investigate the response of the NAM to increased GHG forcing, we used a suite of models from the CMIP5 archive that included continuous ensemble members from
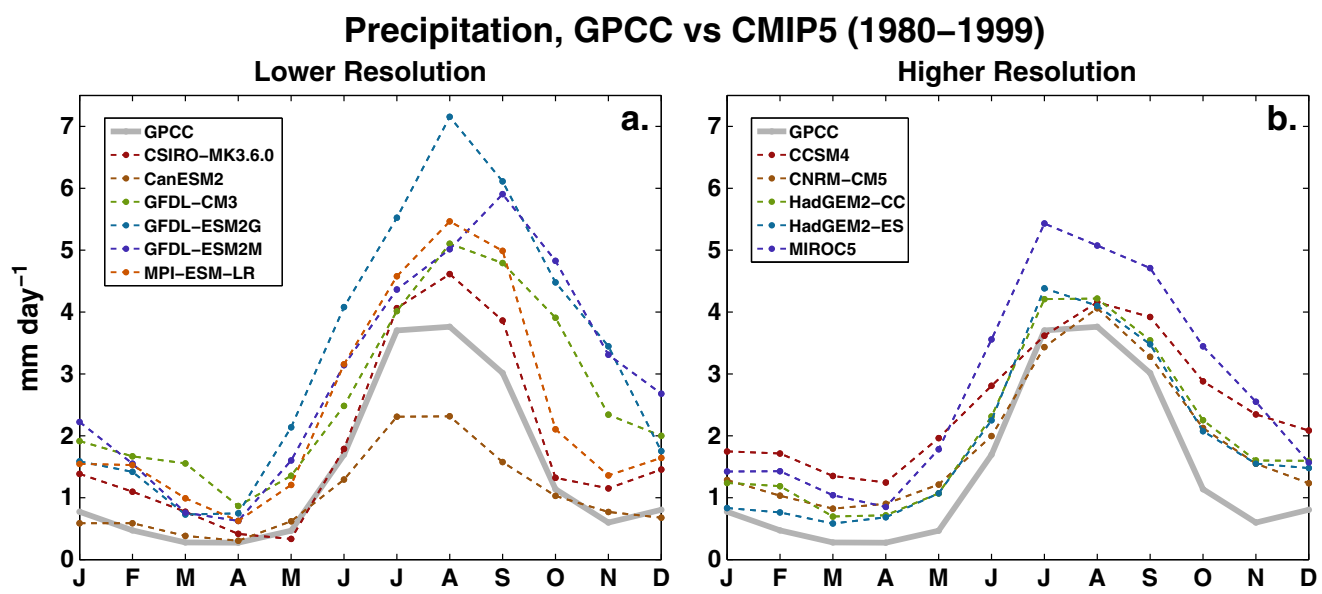

Figure 2. Comparison of precipitation climatologies (1980-1999) for the core NAM region in the CMIP5 historical simulations (dashed lines) and the GPCC precipitation data (grey line). Lowest resolution models are shown in (a), highest resolution models are displayed in (b). Where multiple ensemble members were available, the model climatologies represent ensemble averages.

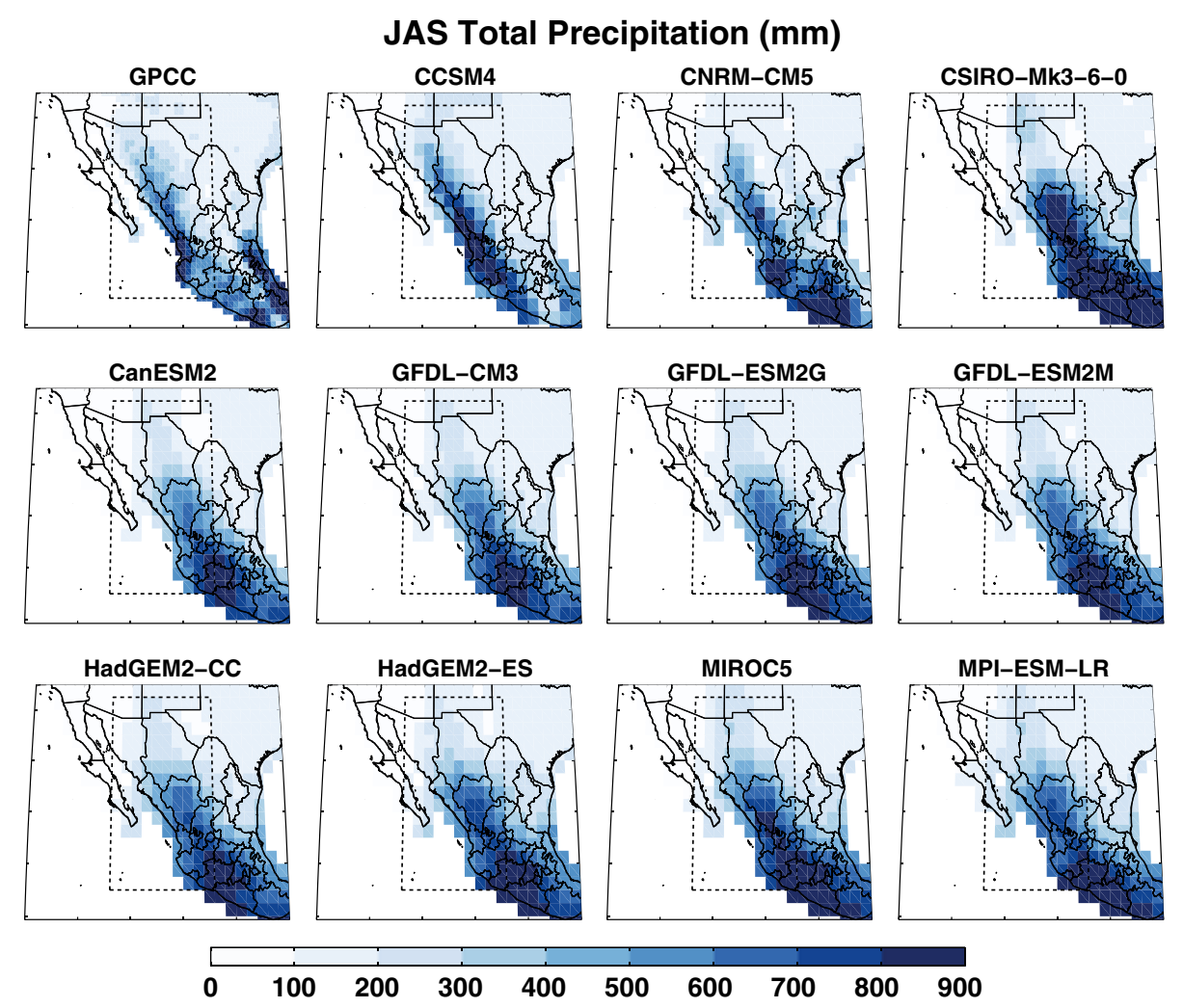

Figure 3. Climatological average (1980-1999) total monsoon season (July-August-September) precipitation $(\mathrm{mm})$ from the GPCC data and each model in our analysis. Where multiple ensemble members were available, model precipitation totals reflect the average across all ensemble members. 
$\triangle$ Precip, RCP 8.5, $\mathrm{mm} \mathrm{d}^{-1}$ (2080-2099 vs 1980-1999)
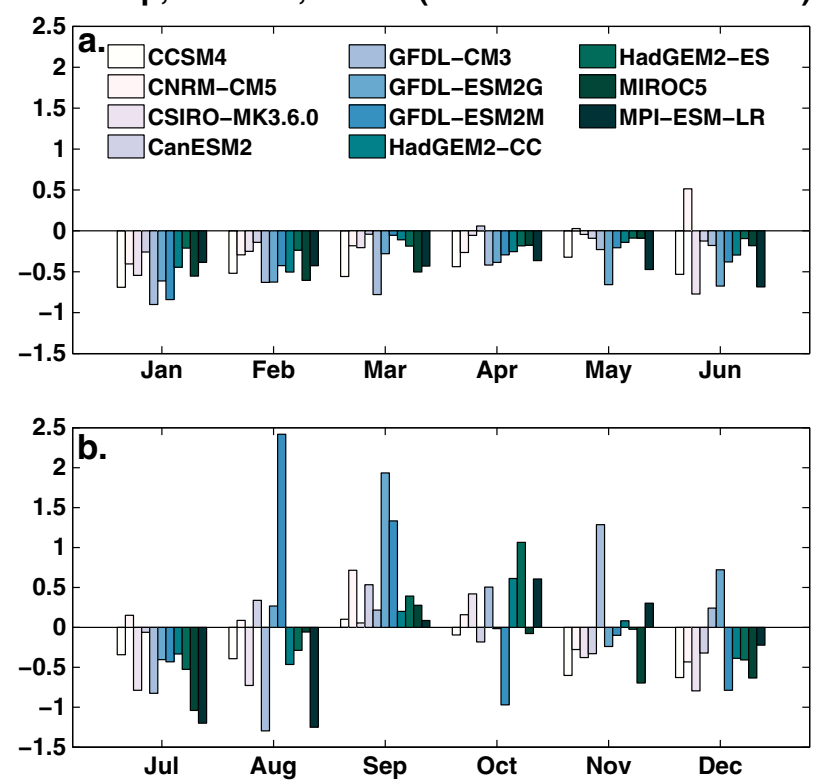

Figure 4. Ensemble average monthly precipitation anomalies $\left(\mathrm{mm} \mathrm{day}^{-1}\right)$ for the core NAM region: January through June (a) and July through December (b). Anomalies are calculated as the mean precipitation for 2080-2099 (RCP 8.5 scenario) minus the mean precipitation for 1980-1999 (historical scenario). the historical (1850-2005) and RCP 8.5 (2006-2099) forcing scenarios [Moss et al., 2010; van Vuuren et al., 2011] (11 models; Table 1). The historical simulations are forced by observed transient climate forcings from the instrumental period (solar, volcanoes, GHG concentrations, etc) using a fully coupled ocean model. Initial conditions are based on a long equilibrium control run with fixed pre-industrial forcings. The RCP 8.5 simulation is one of a suite of future GHG forcing scenarios with relatively high GHG concentrations, designed so that anthropogenic radiative forcing will be approximately $8.5 \mathrm{~W} \mathrm{~m}^{-2}$ by 2100 . Initial conditions for the RCP 8.5 scenario start from the end of the historical runs. We restricted our analyses to those models that reproduced the seasonality of precipitation over the NAM core region in the historical scenarios, based on a comparison with the GPCC data.

[8] To assess the response of the NAM to GHG forcing, we used precipitation rate $\left(\mathrm{mm} \mathrm{day}^{-1}\right)$, ET $\left(\mathrm{mm} \mathrm{day}^{-1}\right)$, and moist static energy (MSE) budgets $\left(\mathrm{kj} \mathrm{kg}^{-1}\right)$ at the surface and $700 \mathrm{hPa}$. The difference between the MSE of a rising parcel (which becomes saturated at the lifting condensation level) and the saturated MSE at a given height in the free atmosphere is proportional to the parcel's thermal buoyancy at that height [e.g., Khairoutdinov and Randall, 2006; Randall, 2012]. If the MSE of a rising, saturated parcel exceeds the saturated MSE of the free air environment, the parcel will have positive buoyancy, and the column will be unstable and favor convection

Multi-Model Mean Precip, mm d-1 (1980-2099)
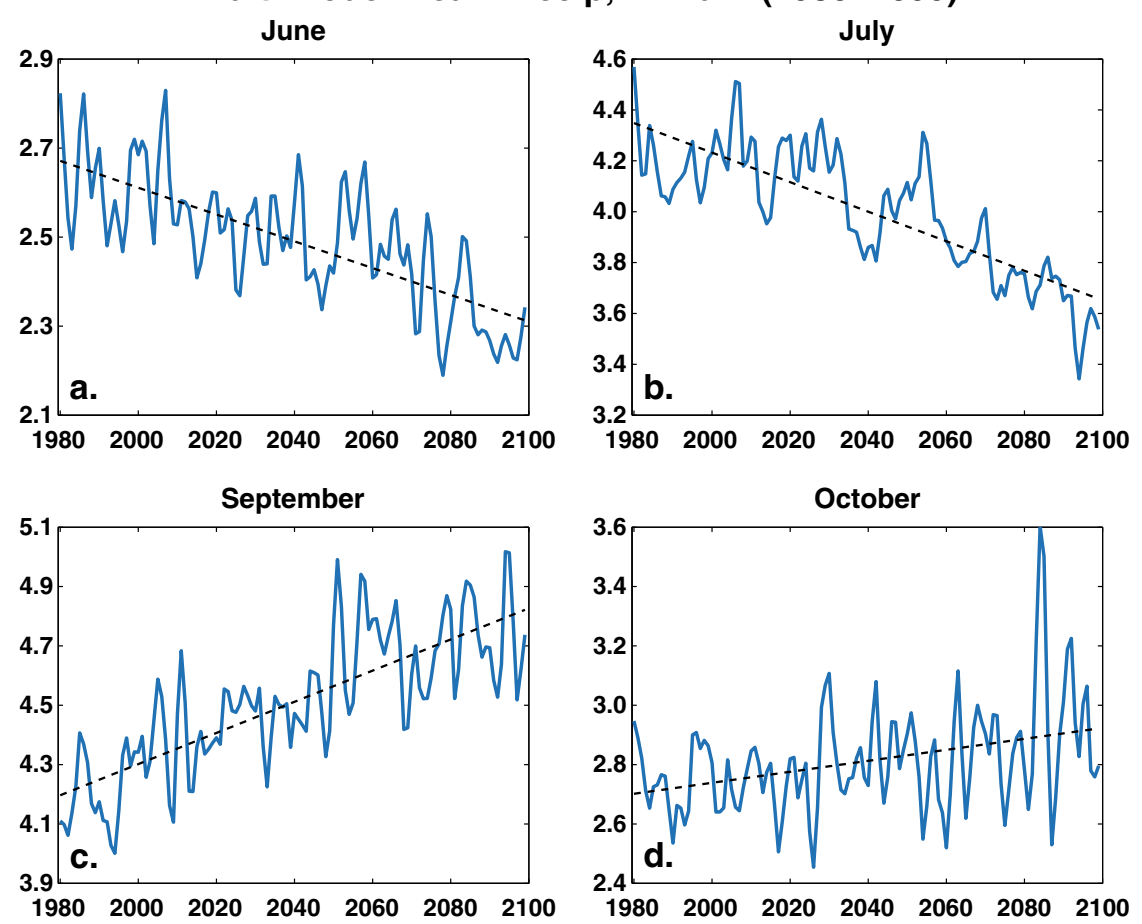

Figure 5. Changes in NAM precipitation $\left(\mathrm{mm} \mathrm{day}^{-1}\right)$ over the core NAM region, averaged across all models for the continous historical (1980-2005) and RCP 8.5 (2006-2099) scenarios: June (a), July (b), September (c), and October (d). Solid blue lines represent the cross-model mean (smoothed with a 5-year lowess filter). Dashed black lines are the trends estimated from a best fit linear least squares regression for 1980 to 2099. 
and precipitation. For MSE at the surface, representing the saturated parcel, we calculate:

$$
M S E_{\text {surf }}=C_{p} T_{2 m}+L_{v} q_{2 m}
$$

where $C_{p}$ is the specific heat of dry air at constant pressure, $T_{2 m}$ is the 2-meter surface air temperature, $L_{v}$ is the latent heat of vaporization, and $q_{2 m}$ is the surface specific humidity. For MSE of the free atmosphere, we use saturated MSE at $700 \mathrm{hPa}$ (the lifting condensation level in these models was generally below $700 \mathrm{hPa}$ ):

$$
M S E_{700}^{*}=C_{p} T_{700}+L_{\nu} q_{700}^{*}+g z_{700}
$$

where $C_{p}$ is the specific heat of dry air at constant pressure, $T_{700}$ is the $700 \mathrm{hPa}$ air temperature, $L_{v}$ is that latent heat of vaporization, $q_{700}^{*}$ is the saturation specific humidity at $700 \mathrm{hPa}, g$ is the gravitational constant, and $z_{700}$ is the height of the $700 \mathrm{hPa}$ layer above the surface.

[9] Declines in ET and surface humidity in the pre- and early monsoon season with increased GHG forcing will be expected to suppress precipitation (the local mechanism). If GHG forced increases in $M S E_{700}^{*}$ are greater than $M S E_{\text {surf }}$, this indicates an overall increase in stability driven by tropospheric warming, which will also be expected to suppress convection and precipitation (the remote mechanism). For the stability calculations, all the necessary variables were not available in the CMIP5 database for GFDL-CM3, MPI-ESM-LR, and three of the ensemble members from CCSM4.

\section{Results}

\subsection{Climatology}

[10] Eleven models from the CMIP5 archive reproduce, to varying degrees, the seasonal cycle of NAM precipitation (Figure 2). All of the selected models (Table 1) simulate a dry season early in the calendar year (January through April), although with large wet biases relative to the GPCC observations. Model transitions into the main monsoon season are generally consistent with observations, although the wet biases continue during this season and through the rest of the year. Notably, most models had some difficulty reproducing the rapid retreat of the monsoon in October, and instead simulated a relatively slow decline in precipitation during the post monsoon season. Little difference is seen between the six lowest (Figure 2a) and five highest (Figure $2 \mathrm{~b}$ ) resolution models, although wet biases during the main monsoon season appear to be improved in the higher resolution models. Spatially, the wet biases in the models during the JAS summer monsoon season (Figure 3) are concentrated in the southern end of the core NAM region and along the eastward flank of the Sierra Madre Occidental mountain range. Precipitation amounts are reasonably well simulated at the northern end of the NAM where it enters the southwest U.S.

\subsection{Precipitation Response}

[11] In response to increased GHG forcing in the RCP 8.5 scenario, all of the models project nearly uniform drying during the pre-monsoon winter dry season (January-March)

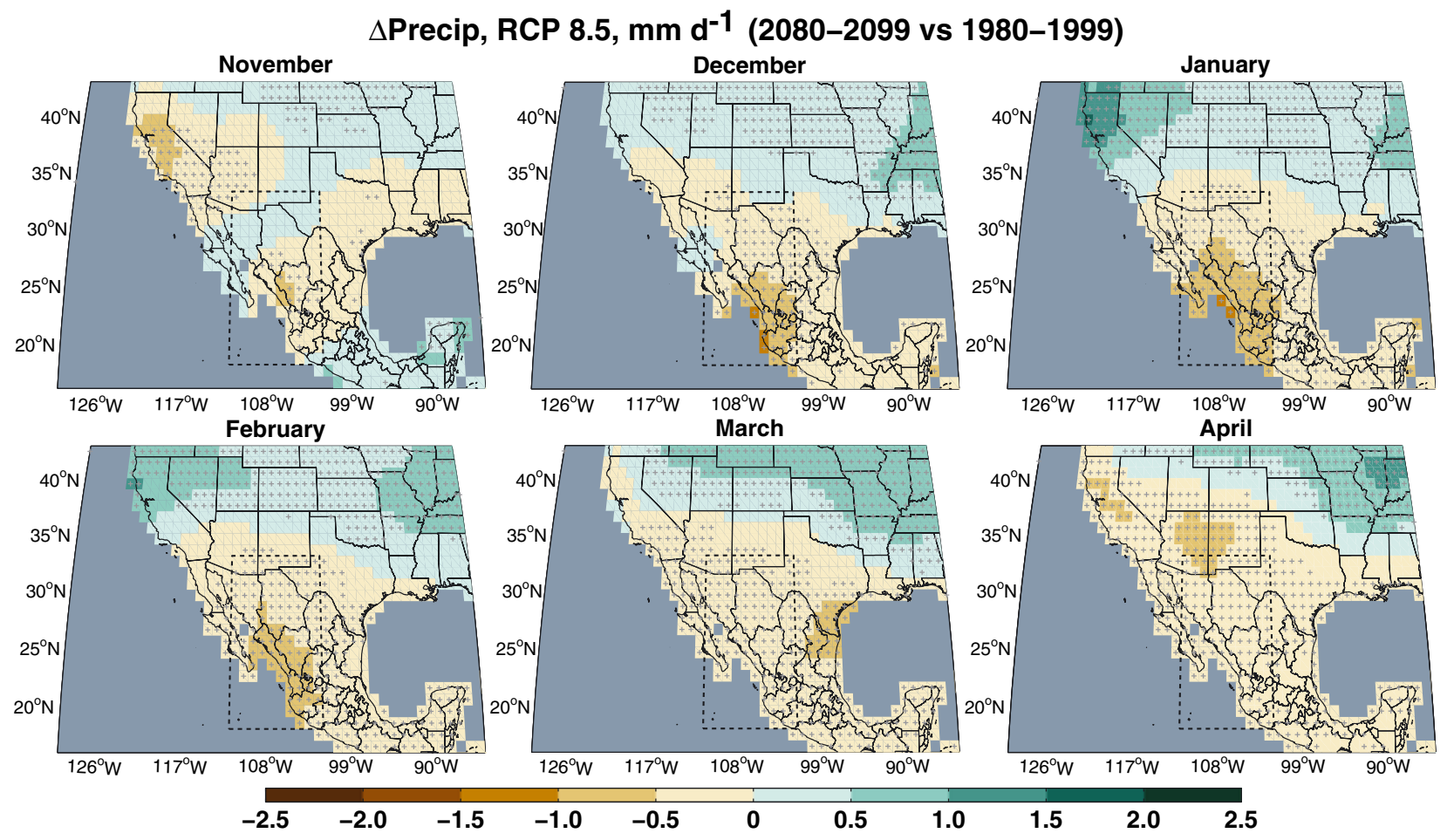

Figure 6. Multi-model mean precipitation differences $\left(\mathrm{mm} \mathrm{day}^{-1}\right)$, calculated as mean precipitation for 2080-2099 (RCP 8.5 scenario) minus the mean precipitation for 1980-1999 (historical scenario) for the dry season (November-April). Core NAM region is outlined with the black dashed lines. Grey crosses indicate cells for which the sign of the change in at least 9 of the 11 models agrees with the sign of the change in the multi-model mean. 


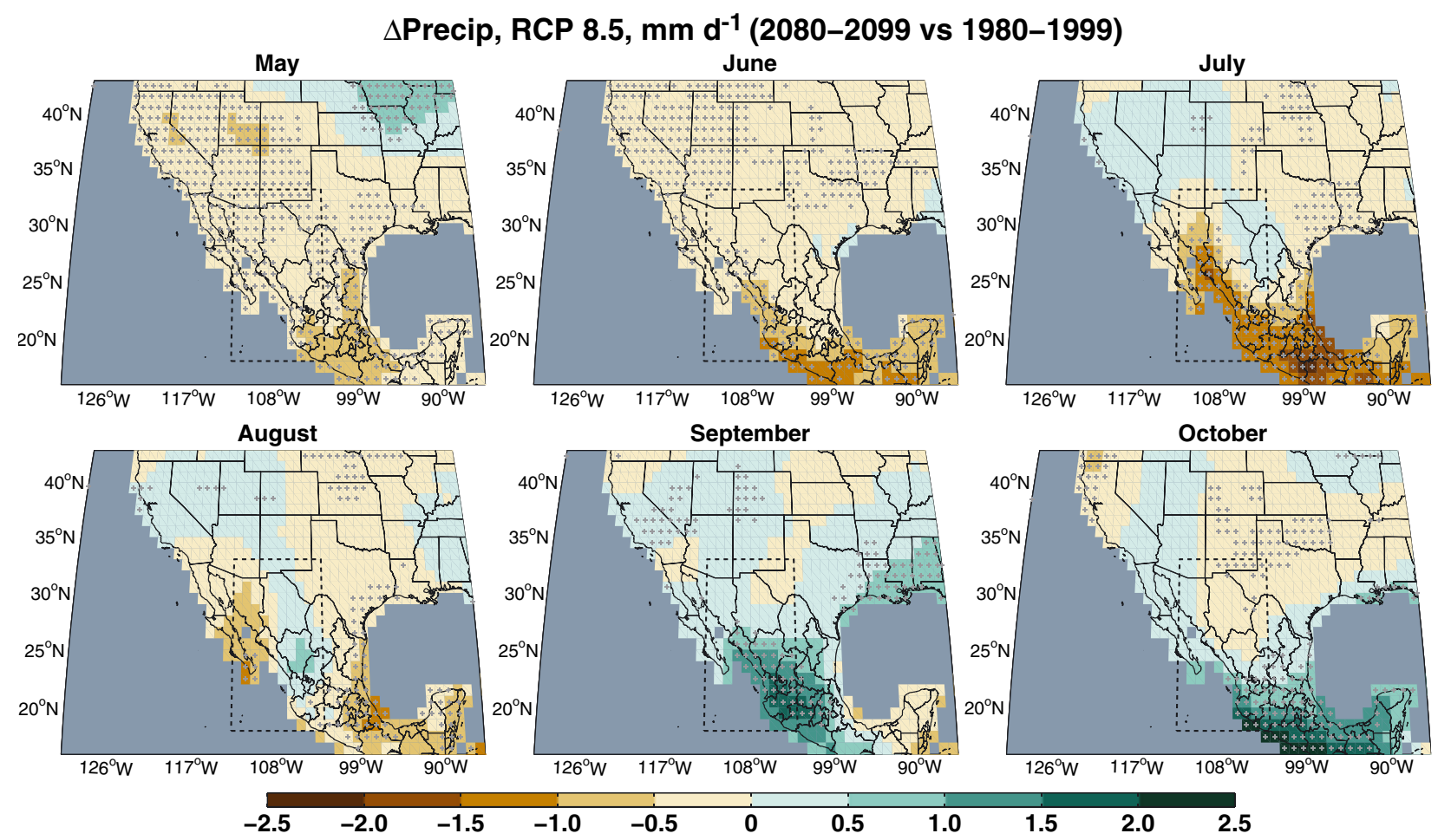

Figure 7. Multi-model mean precipitation differences $\left(\mathrm{mm} \mathrm{day}^{-1}\right)$, calculated as mean precipitation for 2080-2099 (RCP 8.5 scenario) minus the mean precipitation for 1980-1999 (historical scenario) for the extended monsoon season (May-October). Core NAM region is outlined with the black dashed lines. Grey crosses indicate cells for which the sign of the change in at least 9 of the 11 models agrees with the sign of the change in the multi-model mean.

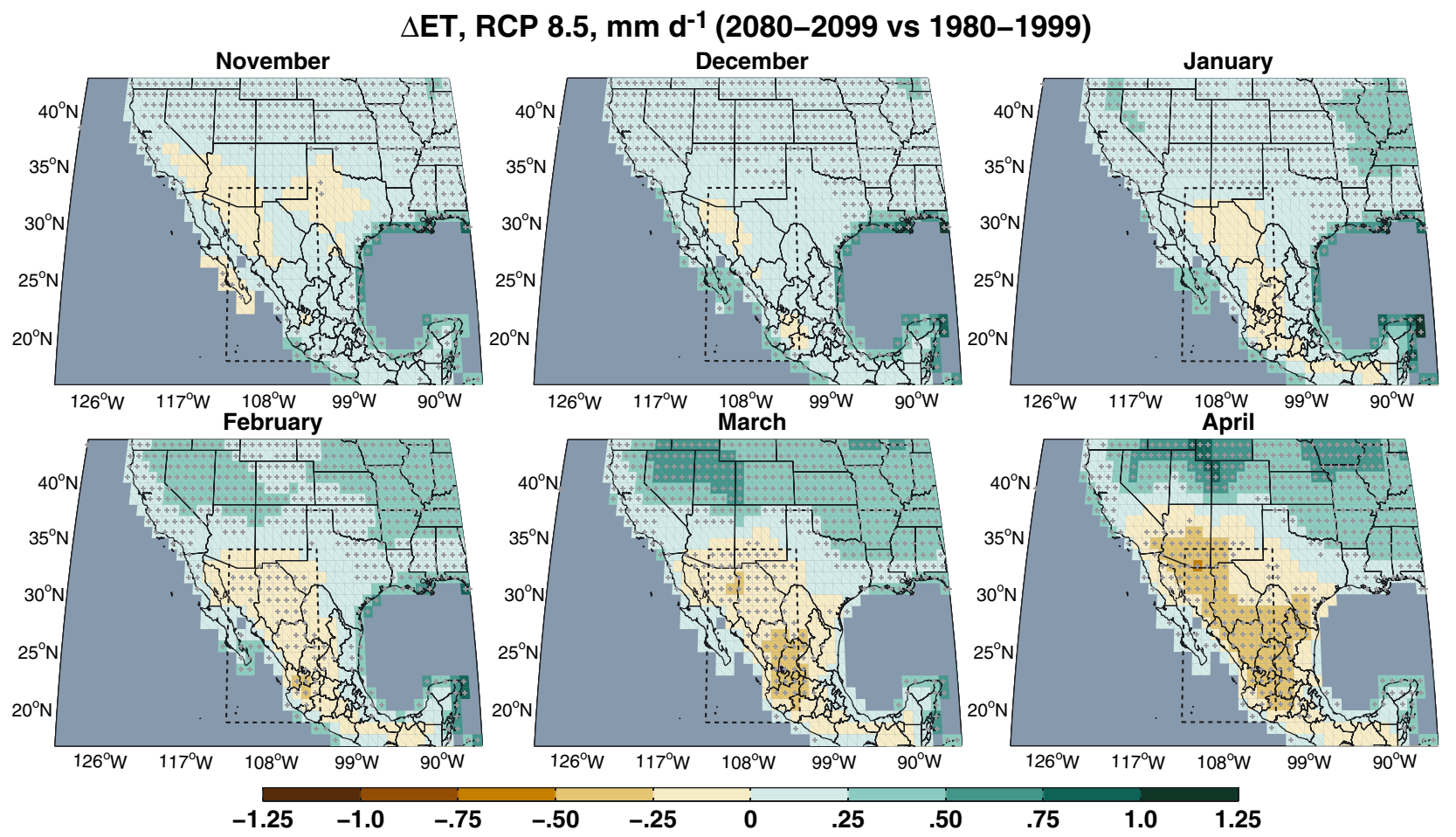

Figure 8. Multi-model mean evapotranspiration (ET) differences ( $\left.\mathrm{mm} \mathrm{day}^{-1}\right)$, calculated as mean land surface ET for 2080-2099 (RCP 8.5 scenario) minus the mean land surface ET for 1980-1999 (historical scenario) for the dry season (November-April). Core NAM region is outlined with the black dashed lines. Grey crosses indicate cells for which the sign of the change in at least 9 of the 11 models agrees with the sign of the change in the multi-model mean. Colorbar range is reduced relative to the precipitation maps in Figures 6 and 7. 
(Figure 4). These trends are consistent with other analyses showing declines in cold season precipitation over much of the southwest with increased GHG forcing [e.g., Seager et al., 2007]. Most models also show a decline in precipitation during the transition and early portion of the monsoon season (June-July) and increased precipitation at the end of the monsoon (September-October), indicating a shift in monsoon timing and seasonality to later in the year.

[12] Trends over 1980-2099 in the multi-model mean precipitation during these four months are significant $(p \leq 0.05)$, based on a best fit linear least squares regression (Figure 5). Precipitation declines during June and July are $\sim 15 \%$, while increases during September and October are $\sim 14 \%$ and $\sim 6 \%$, respectively. Notably, trends in total average monsoon season (JAS) precipitation are weak $(\sim 2 \%$ decline $)$ and insignificant $(p>0.05)$, indicating that early monsoon season declines in precipitation are largely balanced by increases late in the monsoon. Trends over the extended monsoon season (June through October) are significant $(p<0.05)$, but are similarly weak $(\sim 2 \%$ decline). Averaged across the entire year, precipitation in the multi-model mean over this region declines by $\sim 26 \%$ from 1980 to 2099 , driven primarily by drying during the winter and the early summer monsoon and hence influenced by the model wet biases during this season.

[13] Drying during the winter and spring (November-April) in the core NAM region is robust across the CMIP5 models, part of a larger pattern of subtropical drying in response to increased GHG forcing (Figure 6; grey crosses indicate regions where at least 9 of the 11 models agree with the sign of the multi-model mean). From May through October, the multi-model mean precipitation response is largest and most robust across models in the southern end of the core NAM region and along the Pacific coast (Figure 7). Large precipitation reductions begin in June and intensify in July. During August, the peak month of the monsoon season, the multi-model mean shows drying in the western part of the NAM domain and increases in precipitation in the central region. However, there is little agreement across models regarding the sign or magnitude of the precipitation response during this month (see also Figure 4). Precipitation increases across the southern extent of the NAM during September and October, generally overlapping with the areas of drying earlier in the year (June and July).

\subsection{Local Versus Remote Convective Barrier Mechanisms}

[14] Large areas of reduced ET across the southwest and southern Plains are evident in the multi-model mean (Figures 8 and 9), indicative of soil drying and reduced moisture availability from the land surface. Over the core NAM region, the largest and most robust ET reductions begin in March and April (Figure 8), extending into May (Figure 9). By the time the monsoon is firmly established in June and July, the center of action for the negative ET

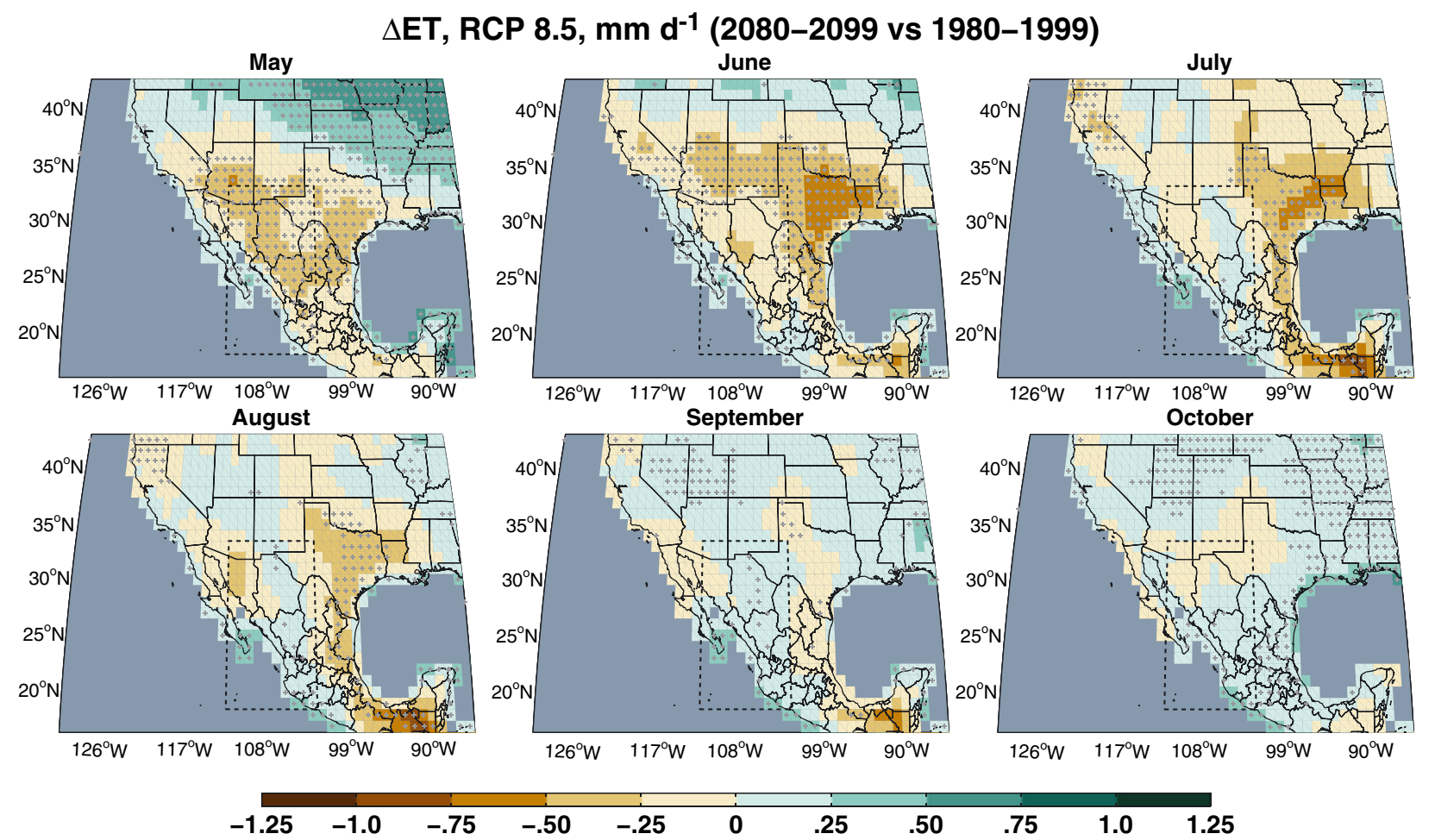

Figure 9. Multi-model mean evapotranspiration (ET) differences ( $\left.\mathrm{mm} \mathrm{day}^{-1}\right)$, calculated as mean land surface ET for 2080-2099 (RCP 8.5 scenario) minus the mean land surface ET for 1980-1999 (historical scenario) for the extended monsoon season (May-October). Core NAM region is outlined with the black dashed lines. Grey crosses indicate cells for which the sign of the change in at least 9 of the 11 models agrees with the sign of the change in the multi-model mean. Colorbar range is reduced relative to the precipitation maps in Figures 6 and 7. 
anomalies moves north and east into Arizona, New Mexico, and Texas, outside of the core NAM region.

[15] Both $M S E_{\text {surf }}$ and $M S E_{700}^{*}$ increase over the core NAM region in the multi-model mean (Figure 10a), leading to net increases in stability during all months $\left(M S E_{700}^{*}-M S E_{\text {surf }}\right.$; Figure 10b). Increases in $M S E_{700}^{*}$ over the NAM are driven by mid-tropospheric warming, part of a global pattern of warming due to increased GHG forcing. The largest increases in $M S E_{700}^{*}$ coincide with the transition into the monsoon season in the late spring and early summer (May to July) and act to suppress convection and precipitation. Conversely, increases in $M S E_{\text {surf }}$ will act to destabilize the atmosphere, favoring convection and precipitation. Increases in $M S E_{\text {surf }}$ are lowest during the winter and early spring, but rise rapidly during the monsoon season and peak in September-October. Combined, trends in $M S E_{\text {surf }}$ and $M S E_{700}^{*}$ lead to the largest increases in stability during the early monsoon season, coinciding with the largest precipitation reductions in June and July (Figures 5 and 7). By the end of the monsoon season in September and October, increases in $M S E_{\text {surf }}$ compensate for increases in $M S E_{700}^{*}$, resulting in only minor increases in stability averaged across the core NAM region. June and July show large increases in stability across the NAM domain (Figure 11), while over the southern and coastal areas of the NAM region $M S E_{\text {surf }}$ increases in September and October leading to decreased
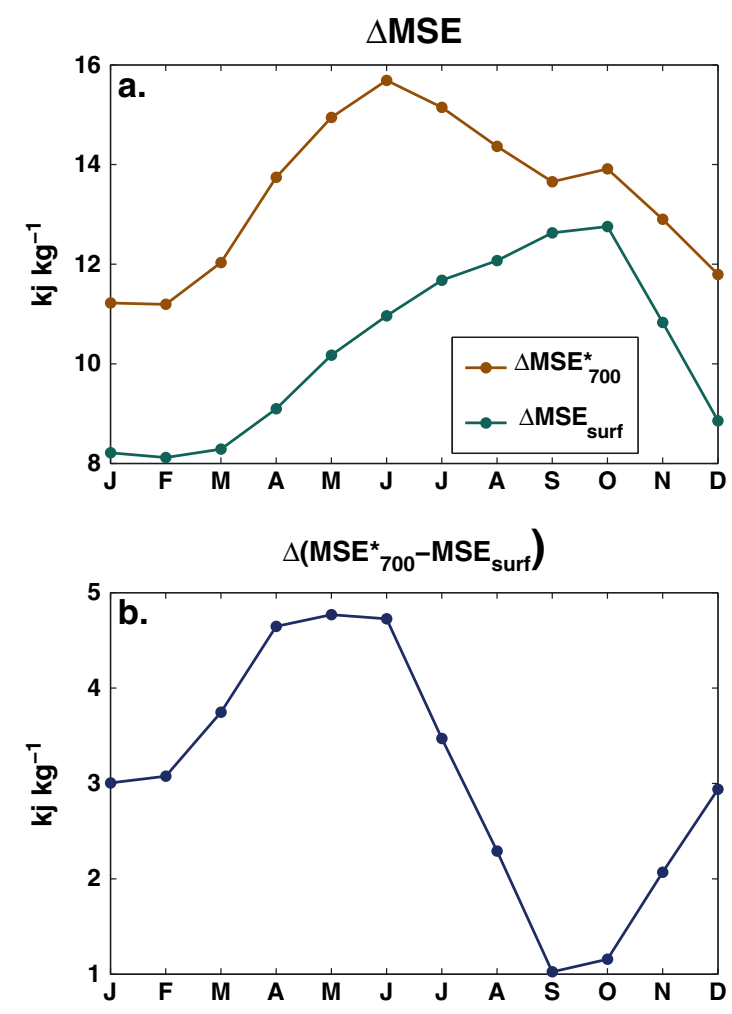

Figure 10. Multi-model mean monthly changes in a) $M S E_{\text {surf }}$ and $M S E_{700}^{*}$ b) and $M S E_{700}^{*}$ minus $M S E_{\text {surf }}$, averaged over the core NAM region $\left(\mathrm{kj} \mathrm{kg}^{-1}\right)$. Differences are for 2080-2099 (RCP 8.5 scenario) minus 1980-1999 (historical scenario). Increases in $M S E_{\text {surf }}$ favor convection and precipitation while increases in $M S E_{700}^{*}$ act to stabilize the atmosphere, inhibiting convection and precipitation. stability, coincident with the areas where precipitation increases during these months.

[16] To isolate the primary drivers of the stability and $M S E$ trends (temperature versus moisture), we recalculated changes in $M S E_{\text {surf, }}$ alternately assuming no change in $T_{2 m}$ or $q_{2 m}$ (Figure 12). Seasonal patterns in $\triangle M S E_{\text {surf }}$ are dominated by the change in the surface moisture term, $L_{v} q_{2 m}$. As the monsoon develops, increases in $L_{v} q_{2 m}$ rapidly increase until reaching a maximum during SeptemberOctober, coinciding with the smallest overall increases in stability and the largest increases in precipitation. Changes in the surface temperature term $C p T_{2 m}$, conversely, are small with a relatively uniform increase across all months. Surface moisture availability is therefore an important modulator of trends in the $M S E_{\text {surf }}$ budget, stability regime, and precipitation response over the core NAM region.

\section{Discussion and Conclusions}

[17] Recent analyses of GCM simulations [e.g., Biasutti and Sobel, 2009; Seth et al., 2011] suggest that increased GHG forcing will lead to a delay in the seasonal cycle of many monsoon regions. This includes the NAM, a region where GCMs have historically had difficulty simulating the dynamics and seasonal cycle of precipitation [Kim et al., 2008]. Here we show, using a new suite of state of the art GCM simulations from the CMIP5 archive, that delays in monsoon onset and retreat are a robust response of the NAM to increased GHG forcing. By the end of the twenty-first century, early monsoon season (June-July) precipitation significantly declines, a change that is largely balanced by late season (September-October) increases, resulting in small and largely insignificant changes in total monsoon season precipitation. Precipitation declines early in the monsoon are caused by increases in tropospheric stability forced by GHG warming in the troposphere ( $M S E_{700}^{*}$; the remote mechanism), modulated by available moisture at the surface $\left(L_{v} q_{2 m}\right.$ in the $M S E_{\text {surf }}$ budget and ET; the local mechanism). By the end of the monsoon season, available moisture near the surface is sufficient to overcome this enhanced convective barrier, and precipitation increases. Trends in annual mean precipitation from our analysis, however, are consistent with previous investigations of Mexico and the Southwest [Seager et al., 2007; Seager and Vecchi, 2010], with overall annual drying still expected to occur, despite little change in total monsoon season rainfall.

[18] We limited our analysis to those CMIP5 models that were able to reproduce the observed seasonal cycle of precipitation in the NAM region. Even given this filtering, however, our results and interpretations may be complicated by other deficiencies in the model climatologies. For example, substantial positive precipitation biases are apparent in nearly all 11 models throughout the year (Figure 2). During the pre-monsoon dry season (January-April), these large biases likely translate to wetter than observed soils which may artificially enhance the impacts of soil moisture drying at monsoon onset. As part of these biases, nearly all the models also have a much more gradual withdrawal of the monsoon in the fall post-monsoon months (OctoberDecember). This may be indicative of land-atmosphere coupling that is too strong in the models, allowing the 

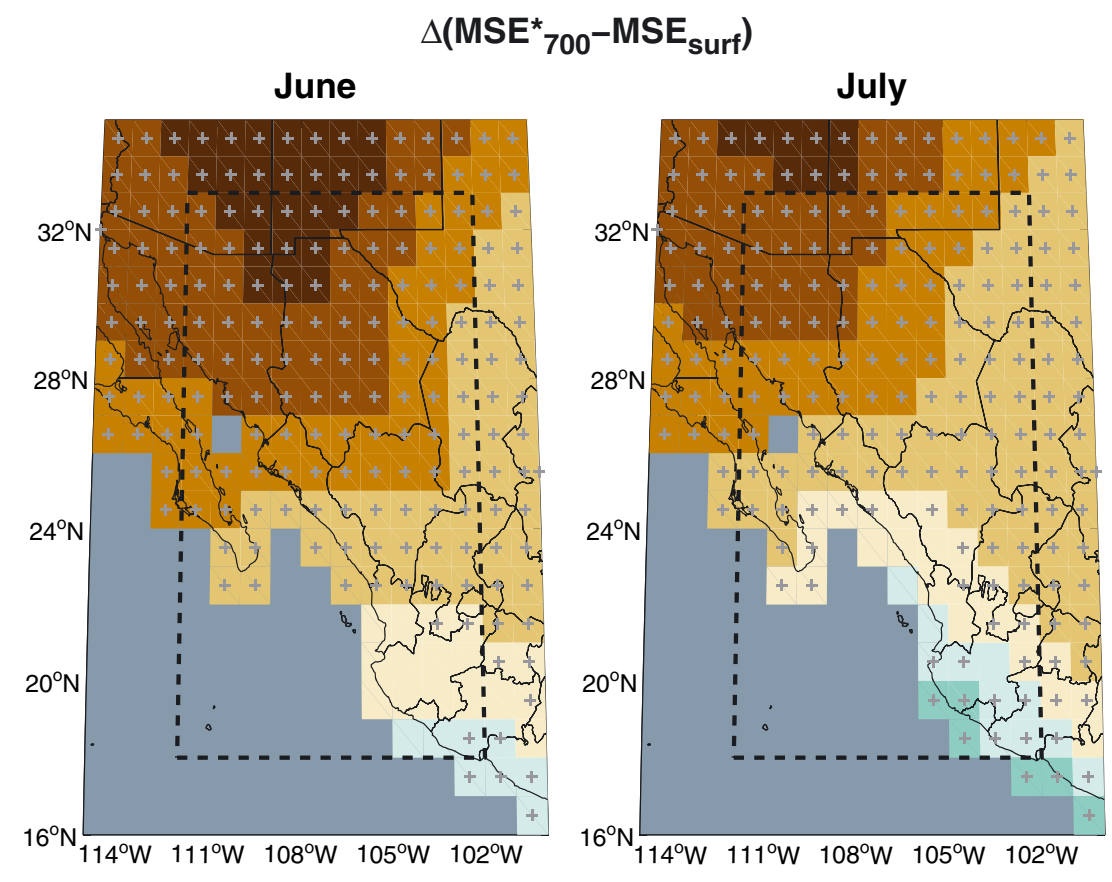

September
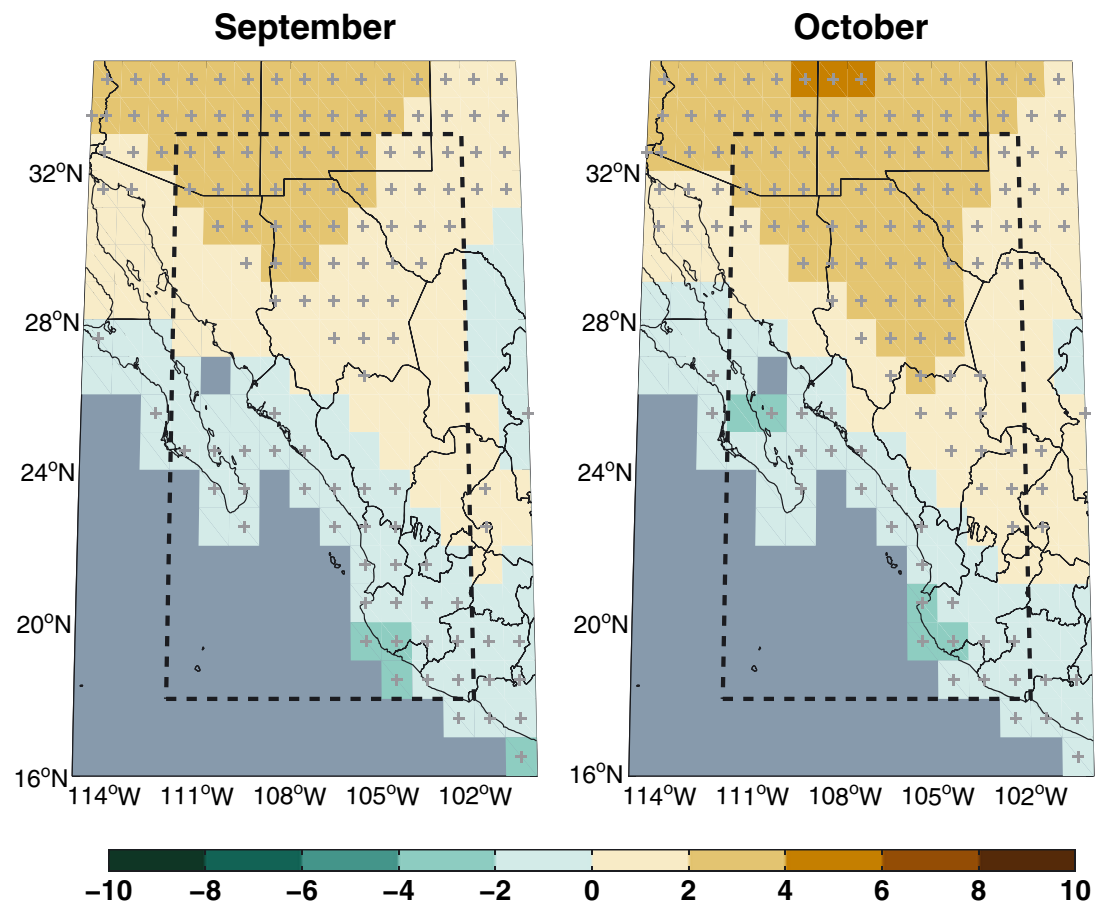

Figure 11. Multi-model mean changes in moist static stability ( $M S E_{700}^{*}$ minus $M S E_{\text {surf }}, \mathrm{kj} \mathrm{kg}^{-1}$ ) for June, July, September, and October. Decreases in moist static stability favor increased precipitation while increases in stability act to suppress precipitation. Differences are for 2080-2099 (RCP 8.5 scenario) minus 1980-1999 (historical scenario). Grey crosses indicate cells where 7 out of 9 models have the same sign as the multi-model mean. The color scheme has been reversed, so that decreases in $M S E_{700}^{*}$ minus $M S E_{\text {surf }}$ (which favor precipitation) are in blue-green and increases (which act to inhibit precipitation) are in brown.

monsoon to persist even as the primary driver of the NAM (heating from solar energy inputs) has already retreated south. Given these caveats, and previous work indicating net drying in Mexico and the North American southwest [Seager et al., 2007; 2009; Seager and Vecchi, 2010], at this point it is not possible to completely rule out an overall drying in the core NAM region until a better representation of the NAM in global models is available.

[19] Despite the focus in the literature on shifts in total precipitation and water resource availability [Barnett et al., 2008; Seager et al., 2007], changes in the timing and seasonal distribution of precipitation may also have significant 


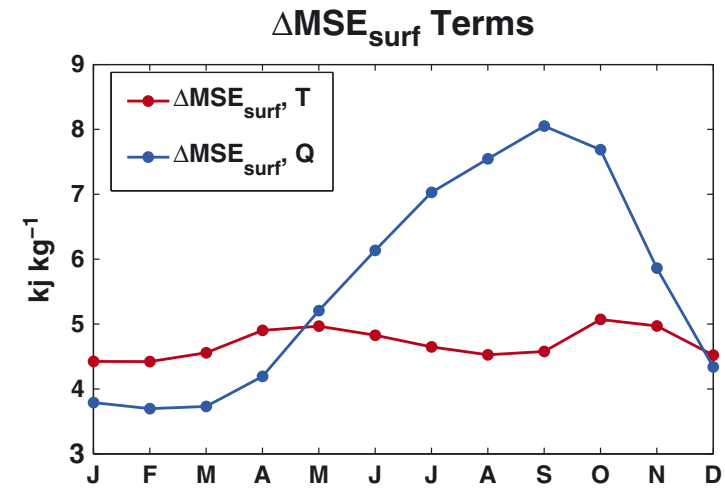

Figure 12. Multi-model mean monthly changes in individual components of the $M S E_{\text {surf }}$ budget, averaged over the core NAM region $\left(\mathrm{kj} \mathrm{kg}^{-1}\right)$. Differences are for 2080-2099 (RCP 8.5 scenario) minus 1980-1999 (historical scenario).

ecological and societal consequences. For example, changes in the timing of the onset of the NAM affect fire and disturbance regimes [Ray et al., 2007; Swetnam and Betancourt, 1998], plant survival and reproduction [Germaine and McPherson, 1998; Ray et al., 2007], and ranching and agriculture [Ray et al., 2007]. Our results, along with previous work, point to the need to consider not only mean changes in precipitation for management and planning within the NAM region, but also changes in the timing and seasonality of future water resource availability.

[20] Acknowledgments. We acknowledge the World Climate Research Programme's Working Group on Coupled Modelling, which is responsible for CMIP, and we thank the climate modeling groups (listed in Table 1 of this paper) for producing and making available their model output. For CMIP, the U.S. Department of Energy's Program for Climate Model Diagnosis and Intercomparison provides coordinating support and led development of software infrastructure in partnership with the Global Organization for Earth System Science Portals. We also gratefully acknowledge Naomi Henderson and Haibo Liu for collecting, managing, and serving the CMIP5 data at Lamont. RS was supported by NOAA awards NAOAR4310137 (Global Decadal Hydroclimate Variability and Change) and NA08OAR4320912 and NSF award AGS0804107. Three anonymous reviewers provided valuable comments that improved the quality of this manuscript. We thank Richard Zou of Hunter High School for assistance on an earlier version of this work. Lamont contribution \#7659.

\section{References}

Adams, D. K., and A. C. Comrie (1997), The North American Monsoon, Bull. Am. Meteorol. Soc., 78(10), 2197-2213.

Barlow, M., S. Nigam, and E. H. Berbery (1998), Evolution of the North American Monsoon System, J. Clim., 11(9), 2238-2257.

Barnett, T. P., et al. (2008), Human-induced changes in the hydrology of the western United States, Science, 319(5866), 1080-1083, doi:10.1126/ science. 1152538

Beck, C., J. Grieser, and B. Rudolf (2005), A New Monthly Precipitation Climatology for the Global Land Areas for the Period 1951 to 2000, in DWD, Klimastatusbericht KSB, 2004, 181-190.

Biasutti, M., and A. H. Sobel (2009), Delayed Sahel rainfall and global seasonal cycle in a warmer climate, Geophys. Res. Lett., 36, L23707, doi:10.1029/2009GL041303.

Germaine, H. L., and G. R. McPherson (1998), Effects of timing of precipitation and acorn harvest date on emergence of Quercus emoryi, J. Veg. Sci., 9(2), 157-160.

Grantz, K., B. Rajagopalan, M. Clark, and E. Zagona (2007), Seasonal shifts in the North American monsoon, J. Clim., 20(9), 1923-1935, doi: http://dx.doi.org/10.1175/JCLI4091.1.
Khairoutdinov, M., and D. Randall (2006), High-Resolution Simulation of Shallow-to-Deep Convection Transition over Land, J. Atmos. Sci., 63(12), 3421-3436, doi:10.1175/JAS3810.1.

Kim, H. J., B. Wang, and Q. Ding (2008), The Global Monsoon Variability Simulated by CMIP3 Coupled Climate Models, J. Clim., 21(20), 5271-5294, doi:http://dx.doi.org/10.1175/2008JCLI2041.1.

Moss, R. H., et al. (2010), The next generation of scenarios for climate change research and assessment, Nature, 463(7282), 747-756, doi:10.1038/nature08823.

Neelin, J. D., C. Chou, and H. Su (2003), Tropical drought regions in global warming and El Nino teleconnections, Geophys. Res. Lett., 30(24), 2275, doi:10.1029/2003GL018625.

Randall, D. (2012), Atmosphere, Clouds, and Climate, Princeton University Press, Princeton. New Jersey.

Ray, A. J., G. M. Garfin, M. Wilder, M. Vásquez-León, M. Lenart, and A. C. Comrie (2007), Applications of monsoon research: Opportunities to inform decision making and reduce regional vulnerability, J. Clim., 20(9), 1608-1627, doi: http://dx.doi.org/10.1175/JCLI4098.1.

Rubel, F., and M. Kottek (2010), Observed and projected climate shifts 1901-2100 depicted by world maps of the Köppen-Geiger climate classification, Meteorol. Z., 19(2), 135-141, doi:http://dx.doi.org/ 10.1127/0941-2948/2010/0430.

Rudolf, B., and U. Schneider (2004), Calculation of gridded precipitation data for the global land-surface using in-situ gauge observations, in Proceedings of the 2nd workshop of the International Precipitation Working Group IPWG, pp. 231-247, EUMETSAT, ISBN 92-9110-070-6, ISSN $1727-432 \mathrm{X}$.

Rudolf, B., H. Hauschild, W. Rueth, and U. Schneider (1994), Terrestrial Precipitation Analysis: Operational Method and Required Density of Point Measurements, Global precipitation and Climate change, NATO ASI Series I, 26, 173-186.

Rudolf, B., T. Fuchs, U. Schneider, and A. Meyer-Christoffer (2003), Introduction of the Global Precipitation Climatology Centre (GPCC), Deutscher Wetterdienst, Offenbach a.M., p. 16.

Rudolf, B., C. Beck, J. Grieser, and U. Schneider (2005), Global Precipitation Analysis Products, Global Precipitation Climatology Centre (GPCC), DWD, Internet publication, pp. 1-8.

Ruff, T. W., Y. Kushnir, and R. Seager (2011), Comparing Twentieth- and Twenty-First-Century Patterns of Interannual Precipitation Variability over the Western United States and Northern Mexico, J. Hydrometeorol., 13(1), 366-378, doi:10.1175/JHM-D-10-05003.1.

Seager, R., and G. A. Vecchi (2010), Greenhouse warming and the 21st century hydroclimate of southwestern North America, Proc. Natl. Acad. Sci., 107(50), 21,277-21,282, doi:10.1073/pinas.0910856107.

Seager, R., M. Ting, M. Davis, M. Cane, N. Naik, J. Nakamura, C. Li, E. Cook, and D. Stahle (2009), Mexican drought: an observational modeling and tree ring study of variability and climate change, Atmósfera, 22(1), 1-31.

Seager, R., et al. (2007), Model projections of an imminent transition to a more arid climate in southwestern North America, Science, 316 , (DOI: 10.1126/science.1139601), 1181-1184.

Seth, A., S. A. Rauscher, M. Rojas, A. Giannini, and S. J. Camargo (2011), Enhanced spring convective barrier for monsoons in a warmer world?, Clim. Chang., 104(2), 403-414, doi:10.1007/s10584-010-9973-8.

Small, E. E. (2001), Influence of soil moisture anomalies on variability of the North American Monsoon System, Geophys. Res. Lett., 28(1), $139-142$.

Swetnam, T. W., and J. L. Betancourt (1998), Mesoscale Disturbance and Ecological Response to Decadal Climatic Variability in the American Southwest, J. Clim., 11(12), 3128-3147, doi:10.1175/1520-0442(1998) 011<3128:MDAERT>2.0.CO;2.

Taylor, K. E., R. J. Stouffer, and G. A. Meehl (2012), An Overview Of CMIP5 And The Experiment Design, Bull. Am. Meteorol. Soc., 93(4), 485-498, doi:10.1175/BAMS-D-11-00094.1.

van Vuuren, D., et al. (2011), The representative concentration pathways: an overview, Clim. Chang., 1-27, doi:10.1007/s10584-011-0148-z.

Vivoni, E. R., K. Tai, and D. J. Gochis (2009), Effects of Initial Soil Moisture on Rainfall Generation and Subsequent Hydrologic Response during the North American Monsoon, J. Hydrometeorol., 10(3), 644-664, doi:10.1175/2008JHM1069.1.

Wild, M., J. Grieser, and C. Schär (2008), Combined surface solar brightening and increasing greenhouse effect support recent intensification of the global land-based hydrological cycle, Geophys. Res. Lett., 35, L17706, doi:10.1029/2008GL034842.

Yatagai, A., O. Arakawa, K. Kamiguchi, H. Kawamoto, M. I. Nodzu, and A. Hamada (2009), A 44-year Daily Gridded Precipitation Dataset for Asia Based on a Dense Network of Rain Gauges, SOLA, 5, 137-140. 